\title{
Association of chronic kidney disease (CKD) and failure to monitor renal function with adverse outcomes in people with diabetes: a primary care cohort study
}

\author{
Andrew P McGovern ${ }^{1 *}$, Benjamin Rusholme1, Simon Jones ${ }^{1}$, Jeremy N van Vlymen ${ }^{1}$, Harshana Liyanage ${ }^{1}$, \\ Hugh Gallagher ${ }^{2}$, Charles RV Tomson ${ }^{3}$, Kamlesh Khunti ${ }^{1}$, Kevin Harris ${ }^{4}$ and Simon de Lusignan ${ }^{1}$
}

\begin{abstract}
Background: Chronic kidney disease (CKD) is a known risk factor for cardiovascular events and all-cause mortality. We investigate the relationship between CKD stage, proteinuria, hypertension and these adverse outcomes in the people with diabetes. We also study the outcomes of people who did not have monitoring of renal function.

Methods: A cohort of people with type 1 and 2 diabetes $(N=35,502)$ from the Quality Improvement in Chronic Kidney Disease (QICKD) cluster randomised trial was followed up over 2.5 years. A composite of all-cause mortality, cardiovascular events, and end stage renal failure comprised the outcome measure. A multilevel logistic regression model was used to determine correlates with this outcome. Known cardiovascular and renal risk factors were adjusted for.

Results: Proteinuria and reduced estimated glomerular filtration rate (eGFR) were independently associated with adverse outcomes in people with diabetes. People with an eGFR $<60 \mathrm{ml} / \mathrm{min}$, proteinuria, and hypertension have the greatest odds ratio (OR) of adverse outcome; 1.58 ( $95 \% \mathrm{Cl} 1.36-1.83)$. Renal function was not monitored in 4460 (12.6\%) people. Unmonitored renal function was associated with adverse events; OR 1.35 (95\% Cl 1.13-1.63) in people with hypertension and OR 1.32 (95\% Cl 1.07-1.64) in those without.
\end{abstract}

Conclusions: Proteinuria, eGFR $<60 \mathrm{ml} / \mathrm{min}$, and failure to monitor renal function are associated with cardiovascular and renal events and mortality in people with diabetes.

Keywords: Unmonitored, Primary care, Cardiovascular risk, Proteinuria, Estimated glomerular filtration rate

\section{Background}

Diabetes mellitus is an increasingly common condition and is associated with increased risk of cardiovascular events and mortality $[1,2]$. Furthermore, diabetes is the most common cause of end-stage renal disease (ESRD); in the United States it account for up to $45 \%$ of all new cases of ESRD [3]. Chronic kidney disease (CKD) is a risk factor for cardiovascular disease and mortality both in the general population $[4,5]$ and amongst people with diabetes [6]. The two components of CKD; reduced estimated glomerular filtration rate (eGFR) and proteinuria

\footnotetext{
* Correspondence: andy@mcgov.co.uk

'Department of Healthcare Management and Policy, University of Surrey, Guildford, UK

Full list of author information is available at the end of the article
}

have been shown to be independently associated with cardiovascular events and mortality in the general population and in high risk populations [7-9].

The National Institute for Health and Clinical Excellence (NICE) currently recommends all people with diabetes in England and Wales regularly have their renal function tested, including testing for albuminuria [10]. However, people with CKD complicating diabetes are not always identified and are sometimes sub-optimally managed in primary care [11]. Early identification of CKD and intervention with renoprotective measures, particularly the use of angiotensin converting enzyme inhibitors (ACEIs) and angiotensin receptor blockers (ARBs), has been shown to be effective in slowing progression of renal disease and in reducing cardiovascular 
events [12-16], and treatment that reduces proteinuria also reduces the risk of progression [17].

We investigated the association of eGFR and proteinuria on adverse vascular and renal outcomes in people with diabetes, with or without hypertension, in a community setting. In addition we investigated the association of these outcomes in people who did not have monitoring of their renal function.

\section{Methods}

We performed a cohort analysis on all adults with diabetes in the Quality Improvement in Chronic Kidney Disease (QICKD) trial database. The QICKD trial was a threearmed cluster randomised controlled trial to analyse the impact of quality improvement interventions on blood pressure in people with renal disease [18]. Randomisation occurred at the primary care practice level. Practices were allocated to usual practice (no intervention), provision of clinical guidelines and prompts, or audit-based education. A reduction was of $2.41 \mathrm{mmHg}$ (CI 0.59-4.29 $\mathrm{mmHg}$; $=$ 0.012) was demonstrated with audit based education. However, neither intervention was found to have any impact on cardiovascular outcomes during the follow-up period. The trial database comprises routinely collected general practice (GP) data from 127 primary care practices across England; a nationally representative sample of urban, sub-urban and rural practices in London, Surrey, Sussex, Leicester,
Birmingham and Cambridge between January 2006 and December 2010 [19]. There were additional records, of varying durations, for each person prior to these dates. Data recorded between January 2006 and June 2008 were used to determine the baseline characteristics of the people included in the study. A second data collection was undertaken at 30 months to obtain follow-up data.

We included all adults with type 1 and 2 diabetes. These patients were identified using a validated method for identifying correctly coded cases of diabetes from UK primary care records [20]. This method included analysis of diabetes read codes (e.g. read codes C10E and C10F are used for type 1 and type 2 diabetes respectively in UK primary care) in combination with documented investigation results. A person was defined as having diabetes if they had read codes for either type 1 or type 2 diabetes or laboratory values consistent with the World Health Organisation (WHO) diagnostic criteria for diabetes [21,22] prior to, or during the baseline period; a fasting blood glucose > $7.1 \mathrm{mmol} / \mathrm{l}$, non-fasting blood glucose $>11.1 \mathrm{mmol} / \mathrm{l}$, or HbA1c $>59 \mathrm{mmol} / \mathrm{mol}$ (7.5\%). People with a recorded diagnosis of gestational diabetes, or elevated blood glucose results during pregnancy were excluded unless they subsequently developed diabetes outside of pregnancy.

England has a registration based primary health care system. With very few exceptions the whole population is registered with a single GP. Patients access non-emergency

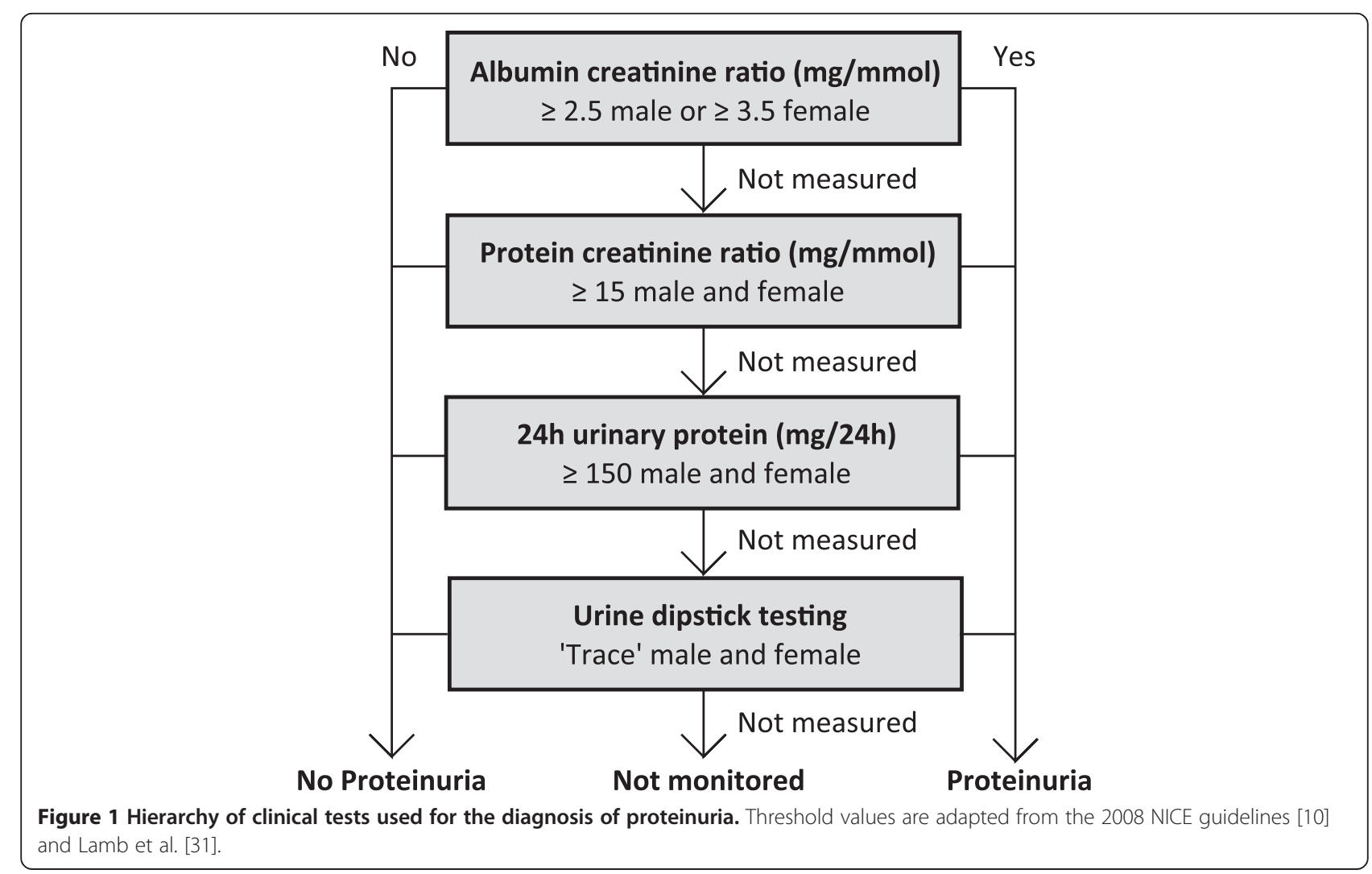


services through their GP and the GP receives letters about all hospital attendances including emergencies. Patients all have a unique ID called NHS number, which is attached to all their medical records. The health system has been progressively computerised since the 1990s [23]. Since 2004 there have been pay-for-performance indicators for chronic disease management, to which CKD was added in 2006 [23]. Remuneration for these is based on extracts from routine computer data [24]. Routinely collected primary care data in the UK, therefore, provides a highly comprehensive patient record.

\section{Outcomes}

A composite outcome measure of incident stroke, transient ischaemic attacks (TIA), myocardial infarction (MI), death, advanced coronary artery disease, heart failure, and progression to end stage renal failure during the follow up period was used. Advanced coronary artery disease comprised revascularisation procedures (percutaneous coronary angioplasty and coronary bypass surgery) and patients with preinfarction syndrome. Preinfarction syndrome consists of newly recorded diagnosis of unstable angina, angina at rest, refractory angina, progressive angina, and acute coronary syndrome not otherwise recorded as a myocardial infarction.

\section{Predictors}

Established predictors of adverse vascular and renal events were controlled for. These comprise: age, sex, ethnicity, deprivation status, smoking status, alcohol intake, body mass index (BMI); comorbid heart failure, hypertension, ischemic heart disease (IHD), advanced coronary artery disease, renal failure requiring dialysis, and dyslipidaemia; a previous history of stroke, transient ischemic attack (TIA), myocardial infarction (MI), coronary artery revascularisation procedures; and current use of aspirin, lipid lowering medication, ACEI or ARB medication, and other anti-hypertensive medications.

Demographic factors were extracted from GP records. Deprivation scores were derived from national statistics using patient postcodes at the point of data extraction (in compliance with data governance standards) [25]. Deprivation scores provide a combined measure of household income, education, healthcare provision, and living environment for the UK at small spatial scales [25]. Each locality is ranked by decile from most deprived to least deprived.

Smoking status and alcohol intake were based on the most recently recorded value for each factor before the start of the follow up period. Hypertension was defined as a recorded diagnosis of hypertension, or repeated blood pressure measurements greater than 130/80 $\mathrm{mmHg}$ [26-28]. A previous history of stroke, TIA, MI, or coronary artery revascularisation procedure and comorbid

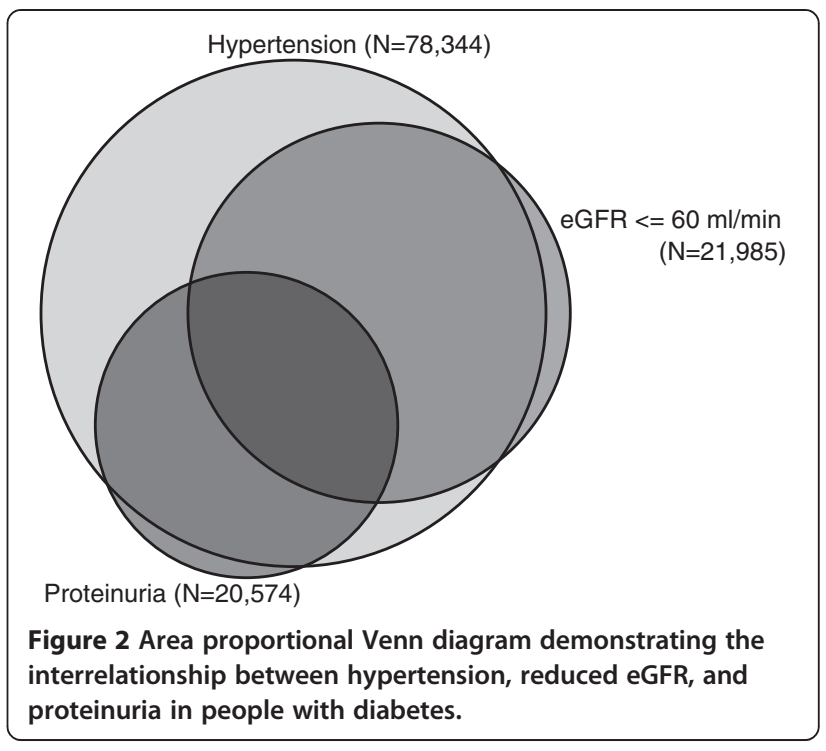

diagnoses of coronary heart failure, IHD, and dialysis were recorded as either present or absent based on the presence of a recorded diagnostic codes. Dyslipidaemia was subdivided into total cholesterol (TC), high density lipoprotein (HDL) cholesterol, and low density lipoprotein (LDL) cholesterol for analysis. Prescription records were used to define medication use. The additional risk factors analysed were: CKD stage, proteinuria (see below), urine albumin creatinine ratio (ACR), and most recent glycated haemoglobin $\left(\mathrm{HbA}_{1 \mathrm{C}}\right)$ result.

The severity of CKD was stratified by stage, using the NICE definition [10], based on two eGFR measurements where available and the presence or absence of proteinuria. People with an eGFR of $60-90 \mathrm{ml} / \mathrm{min}$ or eGFR > $90 \mathrm{ml} / \mathrm{min}$ with proteinuria were classified as having CKD stages $1-2$. People with an eGFR of $<60 \mathrm{ml} / \mathrm{min}$ were classified as having CKD stages 3-5. People who were on dialysis were also included in this category regardless of their creatinine measurements. eGFR values were calculated from serum creatinine using the 4variable Modified Diet in Renal Disease (MDRD) equation $[29,30]$. This remains the standard equation used in UK primary care since the implementation of a national quality standard in 2006 for calculating eGFR across all laboratories in the UK.

Proteinuria was analysed using the diagnostic criteria described by NICE [30]: The presence of proteinuria was determined by examining a hierarchy of clinical tests, with albumin creatinine ratio (ACR) being the highest (Figure 1). Where ACR testing had been done it was distinctly categorised by severity; normal $(<2.5 \mathrm{mg} /$ mmol males, $<3.5 \mathrm{mg} / \mathrm{mmol}$ females), microalbuminuria $(2.5-30 \mathrm{mg} / \mathrm{mmol}$ males, $3.5-30 \mathrm{mg} / \mathrm{mmol} \mathrm{fe}-$ males) and macroalbuminuria (>30 $\mathrm{mg} / \mathrm{mmol}$ ) [31]. 


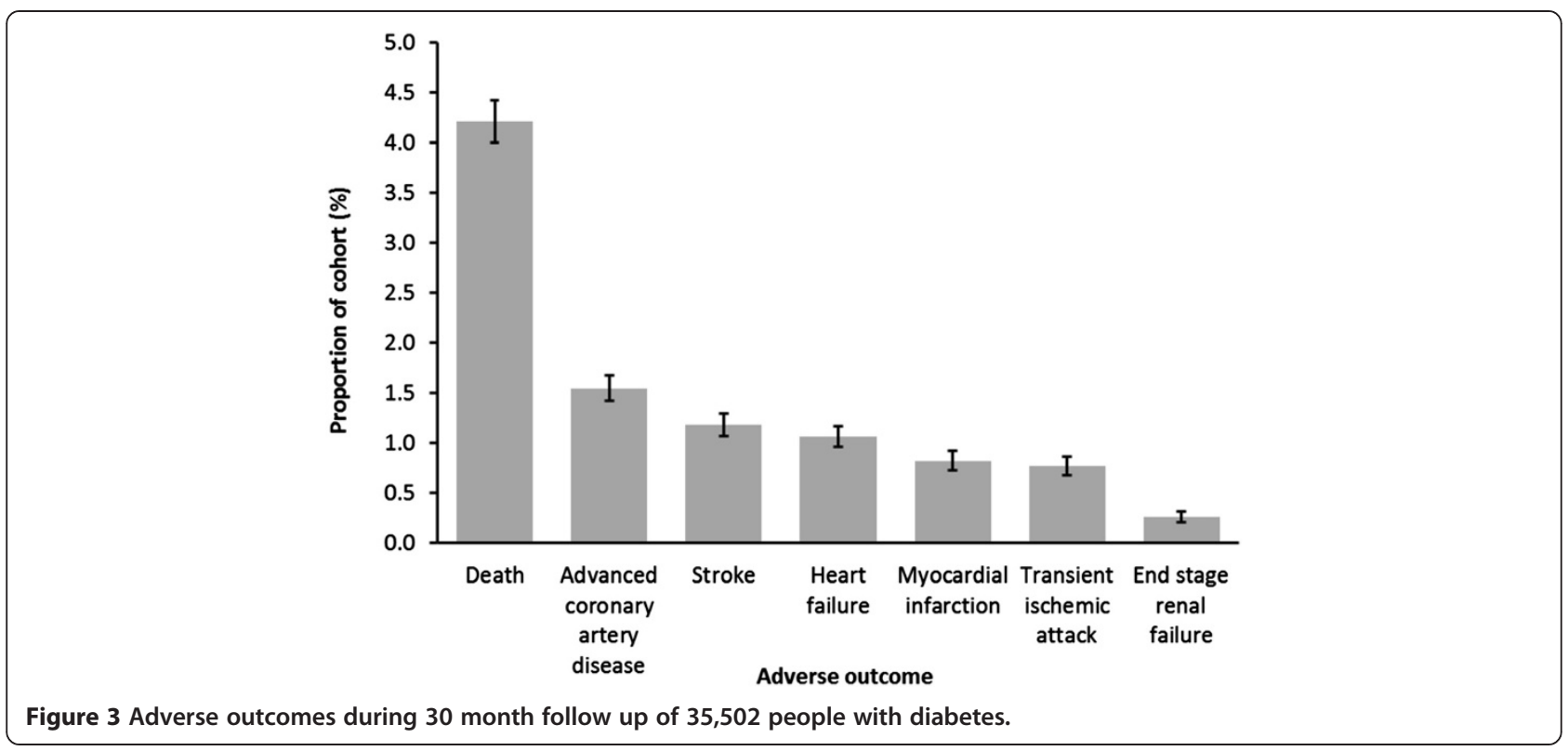

People were defined as having unmonitored renal function if they did not have an eGFR recording and urine protein test during the 30 month baseline period.

\section{Statistical analysis}

The data were first refined, to adjust for inputting errors, by removing numeric values above or below the maximum physiological limits. A complete case analysis was performed to account for the effects of loss to follow-up. A multilevel binary logistic regression model was built to account for variation between primary care practices. Patients were nested within GP practice using a random intercept. This was performed using the statistical package $\mathrm{R}$ and the multilevel $\mathrm{R}$ package lme4 [32]. Model selection was performed using the approach described by Maindonald and Braun [33]; minimising the Bayesian information criterion using backward stepwise elimination. Time to event models (Cox proportional hazard models) were also produced using the statistical package $\mathrm{R}$. Model validation was performed for all models.

A Kaplan-Meier survival analysis was conducted to identify event free survival differences by CKD stage in people with and without hypertension. A logrank test was performed.

\section{Ethical considerations}

No patient identifiable data was used in the analysis described here. The original QICKD study was approved by the Oxford Research Ethics Committee (Committee C). The ethical considerations of the QICKD study are described elsewhere [19,34].

\section{Results}

A total of 741,913 people were included for analysis, of whom 35.914 (4.8\%) had diabetes. We excluded people who died or left the practice before the start of the follow up period $(\mathrm{n}=123)$, or if they were aged less than 18 at the start of the follow up period $(n=142,533)$. From this remaining adult cohort 35,502 people met the diagnostic criteria for diabetes.

The mean age of this cohort was 63.6 years (standard deviation of 14.3 years). Males made up $54 \%$ of the population. Diabetes was coded as type 1 diabetes in 1,202 (3.4\%) people and type 2 in 30,767 (86.7\%). The remaining 3,533 (9.9\%) had other codes consistent with a diagnosis of diabetes or investigations consistent with the diagnostic criteria but where diabetes type was not specified.

Overall 15,813 (44.5\%) people were identified with CKD. Hypertension was found to be present in almost everyone with diabetes and CKD; 15,244 (96.4\%) (Figure 2). 5,862 people were found to have hypertension without CKD.

A total of 3,144 people (8.9\%) in the cohort had an adverse outcome during the 30 month follow up period (Figure 3). All-cause mortality was the most common adverse outcome with 1,495 cases (4.2\%), equating to an annual mortality of 17 per 1,000 person years. Non-fatal cardiovascular events occurred in a total of 1,531 people (4.3\%). 1,691 (4.8\%) people were lost to follow up before suffering an adverse event. These people were included in our final analysis. The demographics of the population are provided in Table 1.

A diagnosis of heart failure, stroke, TIA, ischaemic heart disease, or MI before the start of follow up were all found to be independent predictors of adverse outcome (Table 2). 
Table 1 Clinical characteristics of the 35,502 people with diabetes included for analysis

\begin{tabular}{|c|c|c|c|}
\hline Characteristic & n (\%) & Characteristic & n (\%) \\
\hline Age: mean $( \pm S D)$ & 63.6 years $( \pm 14.3)$ & Investigations & \\
\hline Gender: female & $16,322(45.97)$ & ACR: not monitored & $13,104(36.91)$ \\
\hline Gender: male & $19,180(54.03)$ & ACR: normal & $16,960(56.00)$ \\
\hline Ethnicity & & ACR: microalbuminuria & $4,623(13.02)$ \\
\hline White & $15,222(42.9)$ & ACR: macroalbuminuria & $815(2.30)$ \\
\hline Mixed & $406(1.1)$ & HbA1c: not measured & $3,435(9.7)$ \\
\hline Asian & $6,215(17.5)$ & $\mathrm{HbA} 1 \mathrm{c}:<7.5 \%$ & $19,648(55.3)$ \\
\hline Black & $2,183(6.1)$ & $\mathrm{HbA} 1 \mathrm{c}:>7.5 \%$ & $12,419(35.0)$ \\
\hline Other & 2,187 (6.1) & Total cholesterol: not monitored & $2,046(5.8)$ \\
\hline Not recorded & $9,289(26.2)$ & Total cholesterol: $<5.0 \mathrm{mmol} / \mathrm{l}$ & $31,553(88.9)$ \\
\hline Smoking Status & & Total cholesterol: > $5.0 \mathrm{mmol} / \mathrm{l}$ & $1,903(5.4)$ \\
\hline Not recorded & $7,474(21.05)$ & LDL cholesterol: not monitored & $15,678(44.16)$ \\
\hline Never smoked & $16,349(46.10)$ & LDL cholesterol: normal & $14,612(41.16)$ \\
\hline Current Smoker & $6,620(18.65)$ & LDL cholesterol: high & $5,212(14.68)$ \\
\hline Ex-smoker & $5,059(14.25)$ & HDL cholesterol: not monitored & $5,850(16.48)$ \\
\hline Alcohol Consumption & & HDL cholesterol: normal & $24,372(68.65)$ \\
\hline Not recorded & $12,272(34.57)$ & HDL cholesterol: low & $5,280(14.87)$ \\
\hline No alcohol & $11,250(31.70)$ & No Hypertension & \\
\hline Light alcohol & $10,124(28.52)$ & Renal function not monitored & $2,200(6.20)$ \\
\hline Excess alcohol & $1,725(4.86)$ & No CKD & $15,229(42.90)$ \\
\hline Previous excess alcohol & $131(0.37)$ & CKD all stages & \\
\hline Comorbidities & & Hypertension & $569(1.60)$ \\
\hline Heart failure & $1,550(4.37)$ & Renal function not monitored & $2,260(6.37)$ \\
\hline Dialysis & $97(0.27)$ & No CKD & $5,862(16.51)$ \\
\hline Stroke & $1,438(4.05)$ & CKD stages $1-2$ & $7,581(21.35)$ \\
\hline Transient ischaemic attack & $1,060(2.99)$ & CKD stages 3-5 & $3,987(11.23)$ \\
\hline Ischaemic heart disease & $6,328(17.82)$ & CKD stages $3-5$ with proteinuria & $3,676(10.35)$ \\
\hline Coronary artery operation & $2,322(6.54)$ & LDL cholesterol: not monitored & $15,678(44.16)$ \\
\hline Myocardial infarction & $1,895(5.34)$ & & \\
\hline
\end{tabular}

Abbreviation: $S D$, Standard deviation.

No association with adverse outcome was found with ethnicity, BMI, HbA1c, total cholesterol, and the use of aspirin. These variables were therefore removed from the multilevel logistic regression model.

The odd ratios for adverse outcomes increased with declining renal function, proteinuria, and hypertension (Table 3). Cox regression analysis also demonstrates increasing hazard ratios with declining renal function (Table 4). Event free survival analysis for people with CKD with and without hypertension showed their summative effect on adverse outcomes (Figure 4).

A total of $4,460(12.6 \%)$ people had incomplete CKD screening during the 2.5 year baseline period. This comprised 1,574 (4.4\%) people with no serum creatinine recorded and 3,478 (9.8\%) untested for proteinuria. People with unmonitored renal function, both with and without hypertension, were found to have significantly higher incidence of adverse vascular and renal outcomes than those with normal renal function. People with unmonitored renal function were found to have lower prescription rates of ACE inhibitors and ARBs (41.4\%, 95\% CI 40.2-42.6\%) than people with no evidence of CKD (54.8\%, 95\% CI 54.1$55.4 \%)$ and people with CKD (71.1\%, 95\% CI 70.3-71.9\%). They were also younger, more likely to drink excessive alcohol and smoke, had lower prescription rates of other medications, were more likely to have other missing data, and had worse mean cholesterol values (Table 5).

\section{Discussion}

\section{Principal findings}

We report three principal findings: Both reduced eGFR, and proteinuria are independent predictors of adverse 
Table 2 Univariate and multivariate odds ratios of an adverse outcome over 30 months of follow up, adjusted for CKD and hypertension

\begin{tabular}{|c|c|c|c|c|}
\hline \multirow[b]{2}{*}{ Characteristic: } & \multicolumn{2}{|c|}{ Univariate analysis } & \multicolumn{2}{|c|}{ Multivariate analysis (MLM) } \\
\hline & Odds ratio $(95 \% \mathrm{Cl})$ & $P=$ & Odds ratio $(95 \% \mathrm{Cl})$ & $P=$ \\
\hline Age (years) & $1.06(1.06-1.06)$ & $<0.001$ & $1.05(1.05-1.05)$ & $<0.001$ \\
\hline Gender: female & 1.00 (reference) & - & 1.00 (reference) & - \\
\hline Gender: male & $1.21(1.13-1.31)$ & $<0.001$ & $1.24(1.14-1.36)$ & $<0.001$ \\
\hline \multicolumn{5}{|l|}{ Ethnicity } \\
\hline White & 1.00 (reference) & - & - & - \\
\hline Mixed & $0.61(0.41-0.92)$ & 0.019 & - & - \\
\hline Asian & $1.00(0.99-1.01)$ & 0.488 & - & - \\
\hline Black & $0.98(0.97-1.00)$ & 0.016 & - & - \\
\hline Other & $0.95(0.80-1.13)$ & 0.591 & - & - \\
\hline Missing & $1.02(0.94-1.11)$ & 0.640 & - & - \\
\hline \multicolumn{5}{|l|}{ Smoking Status } \\
\hline Not recorded & $1.18(1.07-1.31)$ & 0.002 & $0.95(0.84-1.08)$ & 0.472 \\
\hline Never smoked & 1.00 (reference) & - & 1.00 (reference) & - \\
\hline Current Smoker & $1.39(1.24-1.57)$ & $<0.001$ & $1.38(1.24-1.54)$ & $<0.001$ \\
\hline Ex-smoker & $1.82(1.61-2.06)$ & $<0.001$ & $1.18(1.05-1.32)$ & 0.005 \\
\hline \multicolumn{5}{|l|}{ Alcohol Consumption } \\
\hline Not recorded & $0.93(0.85-1.01)$ & 0.090 & $1.07(0.96-1.20)$ & 0.223 \\
\hline No alcohol & 1.00 (reference) & - & 1.00 (reference) & - \\
\hline Light alcohol & $0.87(0.79-0.96)$ & 0.004 & $0.88(0.79-0.97)$ & 0.013 \\
\hline Excess alcohol & $1.04(0.87-1.23)$ & 0.688 & $1.24(1.03-1.49)$ & 0.024 \\
\hline Previous excess alcohol & $1.16(0.66-2.02)$ & 0.610 & $1.04(0.56-1.93)$ & 0.895 \\
\hline \multicolumn{5}{|l|}{ Comorbidities } \\
\hline $\mathrm{BMI}\left(\mathrm{kg} / \mathrm{m}^{2}\right)$ & $1.01(0.99-1.02)$ & 0.276 & - & - \\
\hline Heart failure & $3.39(2.99-3.83)$ & $<0.001$ & $1.30(1.13-1.49)$ & $<0.001$ \\
\hline Dialysis & $3.03(1.88-4.89)$ & $<0.001$ & $1.76(1.04-2.99)$ & 0.036 \\
\hline Stroke & $3.96(3.49-4.48)$ & $<0.001$ & $2.26(1.98-2.59)$ & $<0.001$ \\
\hline Transient ischaemic attack & $3.27(2.82-3.79)$ & $<0.001$ & $1.58(1.34-1.86)$ & $<0.001$ \\
\hline Ischaemic heart disease & $3.03(2.80-3.27)$ & $<0.001$ & $1.64(1.47-1.84)$ & $<0.001$ \\
\hline Coronary artery operation & $2.63(2.35-2.94)$ & $<0.001$ & $1.26(1.09-1.44)$ & 0.001 \\
\hline Myocardial infarction & $2.88(2.56-3.24)$ & $<0.001$ & $1.23(1.06-1.42)$ & 0.005 \\
\hline \multicolumn{5}{|l|}{ Investigations } \\
\hline ACR: not monitored & $0.77(0.71-0.84)$ & $<0.001$ & $1.33(1.19-1.50)$ & $<0.001$ \\
\hline ACR: normal & 1.00 (reference) & - & 1.00 (reference) & - \\
\hline ACR: microalbuminuria & $1.46(1.31-1.62)$ & $<0.001$ & $1.16(1.01-1.32)$ & 0.034 \\
\hline ACR: macroalbuminuria & $2.70(2.26-3.23)$ & $<0.001$ & $2.32(1.88-2.86)$ & $<0.001$ \\
\hline HbA1c: not measured & $0.99(0.98-1.01)$ & 0.226 & - & - \\
\hline $\mathrm{HbA} 1 \mathrm{c}:<7.5 \%$ & 1.00 (reference) & - & - & - \\
\hline $\mathrm{HbA} 1 \mathrm{c}:>7.5 \%$ & $1.16(1.01-1.33)$ & 0.224 & - & - \\
\hline Total cholesterol: not monitored & $0.89(0.76-1.05)$ & 0.160 & - & - \\
\hline Total cholesterol: < $5.0 \mathrm{mmol} / \mathrm{l}$ & 1.00 (reference) & - & - & - \\
\hline Total cholesterol: > $5.0 \mathrm{mmol} / \mathrm{l}$ & $0.88(0.74-1.04)$ & 0.134 & - & - \\
\hline LDL cholesterol: not monitored & $1.13(1.05-1.22)$ & 0.002 & $1.23(1.08-1.40)$ & 0.002 \\
\hline LDL cholesterol: normal & 1.00 (reference) & - & 1.00 (reference) & - \\
\hline
\end{tabular}


Table 2 Univariate and multivariate odds ratios of an adverse outcome over 30 months of follow up, adjusted for CKD and hypertension (Continued)

\begin{tabular}{|c|c|c|c|c|}
\hline LDL cholesterol: high & $0.85(0.75-0.96)$ & 0.007 & $1.15(1.01-1.31)$ & 0.030 \\
\hline HDL cholesterol: not monitored & $1.09(0.98-1.20)$ & 0.106 & $1.19(1.02-1.39)$ & 0.025 \\
\hline HDL cholesterol: normal & 1.00 (reference) & - & 1.00 (reference) & - \\
\hline HDL cholesterol: low & $1.13(1.02-1.25)$ & 0.022 & $1.17(1.05-1.31)$ & 0.006 \\
\hline Multilevel model performance: & & & Random effects: & \\
\hline Bayesian information criteria (BIC) & 19022 & & Intercepts for GP practice: & \\
\hline Log-likelihood & -9312 & & Variance & 0.111 \\
\hline ROC curve statistic & 0.767 & & Standard deviation & 0.334 \\
\hline
\end{tabular}

Abbreviations: $M L M$, multilevel model; $C l$, confidence interval.

outcomes. Nearly everyone with diabetes and CKD has hypertension, using the diagnostic threshold recommended by national guidelines. People with unmonitored renal function do worse that those who are monitored and appear to receive suboptimal medical therapies.

The combination of proteinuria and reduced eGFR is associated with the highest risk of adverse outcomes in people with and without hypertension. In people with hypertension and normal eGFR, proteinuria, also significantly increases the odds of adverse outcomes.

Almost all patients with CKD had hypertension whether their CKD was diagnosed by the presence of proteinuria or reduced eGFR. There were, however, a considerable number of people with hypertension and no evidence of renal impairment. However, CKD testing in people with diabetes and hypertension is currently suboptimal: just over $10 \%$ of people had not had appropriate monitoring for CKD by measurement of eGFR and assessment for proteinuria.

People with unmonitored renal function have a higher risk of adverse outcomes than those with normal renal function. This group has the lowest prescription rates of antihypertensive medication, lipid lowering drugs, and aspirin, suggesting people in this group receive suboptimal therapy. They also had higher rates of excess alcohol use and smoking. Whether these differences reflect variation in provision of healthcare or in attitudes to healthcare remains uncertain.

\section{Implications of the findings}

This study highlights the importance of frequent monitoring of eGFR and proteinuria in people with diabetes. In particular, careful monitoring of renal function and testing for proteinuria is essential for people with hypertension and diabetes due to the very high proportion of people with renal impairment in this group.

It is plausible that failure to monitor renal function is associated with wider neglect in clinical management although whether this is due to patient factors or healthcare factors is unclear. Computerised prompts and other recall systems should perhaps focus on those at highest risk i.e. not monitored and not prescribed antihypertensive medication.

\section{Comparison with literature}

The prevalence of CKD stages 3-5 in people with hypertension and diabetes is reported to be $43 \%$, [35] in close

Table 3 Adjusted odd ratios for vascular and renal events and mortality of 35,502 people with diabetes, over 30 months of follow up, by CKD and hypertension category

\begin{tabular}{|c|c|c|c|c|}
\hline & \multicolumn{2}{|c|}{ Univariate analysis } & \multicolumn{2}{|c|}{ Multivariate analysis (MLM) } \\
\hline & Odds ratio $(95 \% \mathrm{Cl})$ & $P=$ & Odds ratio $(95 \% \mathrm{Cl})$ & $P=$ \\
\hline \multicolumn{5}{|l|}{ No Hypertension } \\
\hline Renal function not monitored & $1.21(1.00-1.47)$ & 0.053 & $1.32(1.07-1.64)$ & 0.011 \\
\hline No CKD & 1.00 (reference) & & 1.00 (reference) & - \\
\hline CKD all stages & $3.86(2.15-6.94)$ & $<0.001$ & $1.34(0.93-1.92)$ & 0.117 \\
\hline \multicolumn{5}{|l|}{ Hypertension } \\
\hline Renal function not monitored & $2.07(1.76-2.43)$ & $<0.001$ & $1.35(1.13-1.63)$ & 0.001 \\
\hline No CKD & $1.16(1.01-1.33)$ & 0.038 & $0.97(0.84-1.11)$ & 0.629 \\
\hline CKD stages $1-2$ & $1.66(1.48-1.88)$ & $<0.001$ & $1.19(1.03-1.36)$ & 0.015 \\
\hline CKD stages $3-5$ & $2.39(2.10-2.73)$ & $<0.001$ & $1.13(0.98-1.31)$ & 0.090 \\
\hline CKD stages $3-5$ with proteinuria & $4.38(3.88-4.94)$ & $<0.001$ & $1.58(1.36-1.83)$ & $<0.001$ \\
\hline
\end{tabular}

Abbreviation: $\mathrm{Cl}$, confidence interval. 
Table 4 Adjusted hazard ratios (Cox regression analysis) for adverse outcomes in 35,502 people with diabetes, over $\mathbf{3 0}$ months of follow up, by CKD and hypertension category

\begin{tabular}{lcc}
\hline & Hazard ratio (95\% Cl) & $\mathbf{P =}$ \\
\hline No Hypertension & & \\
\hline Renal function not monitored & $1.49(1.23-1.80)$ & 0.011 \\
No CKD & 1.00 (reference) & - \\
CKD all stages & $1.62(0.76-3.42)$ & 0.060 \\
\hline Hypertension & & \\
\hline Renal function not monitored & $1.55(1.32-1.82)$ & $<0.001$ \\
No CKD & $0.98(0.85-1.12)$ & 0.765 \\
CKD stages 1-2 & $1.31(1.16-1.47)$ & $<0.001$ \\
CKD stages 3-5 & $1.14(1.00-1.31)$ & 0.050 \\
CKD stages 3-5 with proteinuria & $1.72(1.52-1.95)$ & $<0.001$ \\
\hline
\end{tabular}

Abbreviation: $\mathrm{Cl}$, confidence interval. agreement with our value $36.3 \%$; and other community studies report a similar association between CKD and hypertension in people with diabetes [36]. However, we find this proportion increases to $72.2 \%$ if people with CKD stage 1 and 2 are included.

Previous studies in the UK report the prevalence of eGFR screening to be $92-82 \%$ in people with diabetes over a 2 year period [11,37] compared with $95.6 \%$ over 30 months in our study. The prevalence of ACR screening is reported as $55.2 \%$ over 2 years [37], again very similar to our study (63.1\%). The association between absence of assessment for CKD and vascular and renal outcomes has not previously been investigated; though we have previously reported that people not on diabetes disease registers appear to receive suboptimal care [38].

A similar additive association between the proteinuria and eGFR components of renal disease has been reported with vascular and renal events and mortality in the general population and, high risk groups and in people with diabetes [7-9,39-41]. However the combined
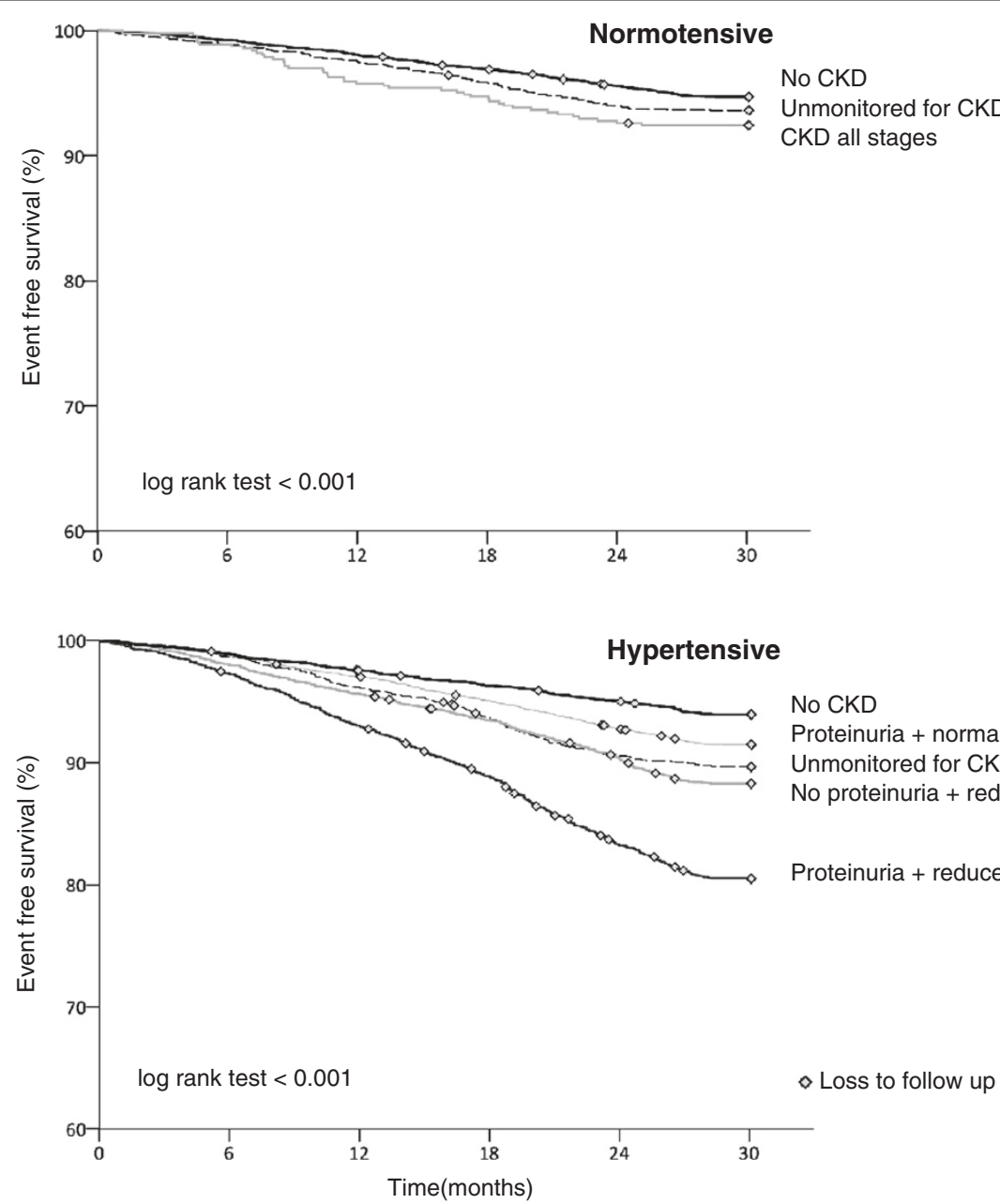

Figure 4 Kaplan-Meier event free survival curves by CKD category in people with normotension and hypertension. 
Table 5 Characteristics of people without monitored renal function compared to those with monitored renal function

\begin{tabular}{|c|c|c|c|}
\hline & $\begin{array}{l}\text { Renal function } \\
\text { not monitored } \\
(\mathrm{N}=4460) n(\%)\end{array}$ & $\begin{array}{c}\text { Renal function } \\
\text { monitored } \\
(\mathrm{N}=31042) n(\%)\end{array}$ & $P=$ \\
\hline Age: mean $( \pm$ SD) & 59.1 years $( \pm 16.5)$ & 64.2 years $( \pm 13.9)$ & $<0.001$ \\
\hline Gender: male & $2,434(54.6 \%)$ & $16,764(53.9 \%)$ & 0.432 \\
\hline Ethnicity & $N=2,227$ & $N=23,986$ & \\
\hline White & $1,232(55.3)$ & $13,990(58.3)$ & \\
\hline Mixed & $37(1.7)$ & $369(1.5)$ & \\
\hline Asian & $480(21.6)$ & $5,735(23.9)$ & \\
\hline Black & $210(9.4)$ & $1,973(8.2)$ & \\
\hline Other & $268(12.0)$ & $1,919(8.0)$ & $<0.001$ \\
\hline Smoking Status & $N=2765$ & $N=25263$ & \\
\hline Never smoked & $1,562(56.5)$ & $14,787(58.5)$ & \\
\hline Current Smoker & $741(26.8)$ & $5,879(18.2)$ & \\
\hline Ex-smoker & $462(16.7)$ & 4,597 (18.2) & $<0.001$ \\
\hline Alcohol Consumption & $N=1,662$ & $N=21568$ & \\
\hline No alcohol & $736(44.3)$ & $10,514(48.7)$ & \\
\hline Light alcohol & $707(42.5)$ & $9,417(43.7)$ & \\
\hline Excess alcohol & $194(11.7)$ & $1,531(7.1)$ & \\
\hline Previous excess alcohol & $25(1.5)$ & $106(0.5)$ & $<0.001$ \\
\hline \multicolumn{4}{|l|}{ Investigations } \\
\hline HbA1c: not monitored & $1,496(33.5)$ & $1,939(6.2)$ & $<0.001$ \\
\hline HbA1c: mean $( \pm S D)$ & $8.16 \%( \pm 2.09)$ & $8.55( \pm 2.07)$ & $<0.001$ \\
\hline $\begin{array}{l}\text { Total cholesterol: not } \\
\text { monitored }\end{array}$ & $1,413(31.7)$ & $633(2.0)$ & $<0.001$ \\
\hline $\begin{array}{l}\text { Total cholesterol: mean } \\
( \pm \text { SD })\end{array}$ & $\begin{array}{l}4.93 \mathrm{mmol} / \mathrm{l} \\
( \pm 1.15)\end{array}$ & $\begin{array}{c}4.60 \mathrm{mmol} / \mathrm{l} \\
( \pm 1.08)\end{array}$ & $<0.001$ \\
\hline $\begin{array}{l}\text { LDL cholesterol: not } \\
\text { monitored }\end{array}$ & $2,510(56.3)$ & $13,168(42.4)$ & $<0.001$ \\
\hline $\begin{array}{l}\text { LDL cholesterol: mean } \\
( \pm S D)\end{array}$ & $\begin{array}{l}2.70 \mathrm{mmol} / \mathrm{l} \\
( \pm 0.99)\end{array}$ & $\begin{array}{l}2.51 \mathrm{mmol} / \mathrm{l} \\
( \pm 0.91)\end{array}$ & $<0.001$ \\
\hline $\begin{array}{l}\text { HDL cholesterol: not } \\
\text { monitored }\end{array}$ & 1,688 (37.8) & $4,162(13.4)$ & $<0.001$ \\
\hline $\begin{array}{l}\text { HDL cholesterol: mean } \\
( \pm \mathrm{SD})\end{array}$ & $\begin{array}{c}1.35 \mathrm{mmol} / \mathrm{l} \\
( \pm 0.39)\end{array}$ & $\begin{array}{c}1.29 \mathrm{mmol} / \mathrm{l} \\
( \pm 0.38)\end{array}$ & $<0.001$ \\
\hline
\end{tabular}

Medications

\begin{tabular}{llll}
\hline ACE/ARBs prescribed & $1,847(41.4)$ & $20,403(65.7)$ & $<0.001$
\end{tabular}

Lipid lowering drugs $\quad 2,134(47.8) \quad 24,136(77.8) \quad<0.001$ prescribed

$\begin{array}{llll}\text { Aspirin prescribed } & 801(18.0) & 9,081(29.3) & <0.001\end{array}$

For ethnicity, smoking status, and alcohol consumption only those with recorded values are included. Abbreviations: $S D$, standard deviation.

impact of these factors with hypertension has not previously been explored in diabetes.

\section{Limitations of the method}

The limitations of this study include those of using routine data [42]. In particular the potential for ascertainment bias in data categories where a significant proportion of data has not been collected (e.g. smoking status and alcohol consumption). For this reason we have included the complete population for analysis with 'not recorded' categories incorporated to identify potential associations with unrecorded data and adverse outcomes. Smoking status and alcohol consumption not recorded were not significantly associated with worse outcomes; OR 0.95 (95\% CI 0.84-1.08) and OR 1.07 (95\% CI 0.961.20) respectively.

Urine samples are frequently tested by clinicians using reagent strips, the results of which may not always be coded, resulting in underreporting of proteinuria testing. However, it is likely that there is a bias for coding positive test results which would not explain the increased risk of adverse outcomes in the apparently unmonitored group.

The causative factors for increased adverse outcomes in people with unmonitored renal function cannot be fully determined. Therefore the benefit of improving screening in this unmonitored group cannot be directly established.

Even with a large cohort the short duration of followup (2.5 years) is also a limitation here. A longer followup period, ideally at least five years would be preferable. Many things, including assessing health economic impact would be possible to estimate given change over 5 years or more. The large sample size makes possible lack of power to identify significant associations unlikely in this study, although weak associations may still be missed.

We have previously demonstrated that the population demographics of the QICKD cohort provide a close age and gender match to the diversity of the English population (from census data) although ethnic minorities appear to be under represented [43]. These results should not, however, be extrapolated to dissimilar populations or different healthcare settings.

\section{Further research}

Further work is needed to demonstrate whether improved screening of renal function in people with diabetes leads in a reduction in vascular and renal events and mortality.

\section{Conclusions}

CKD and proteinuria are associated with worse health outcomes in people with diabetes, and this effect is additive. People with diabetes, who are not monitored for renal disease, have an increased risk of adverse events and appear to receive suboptimal medical therapy.

\section{Competing interests}

The authors declare no competing interests. 


\section{Authors' contributions}

APM, BR, SJ, JNVV, and HL performed the statistical analysis. JNVV, and HL performed data processing and database handling. APM, BR, and SdeL wrote the manuscript. $\mathrm{HG}, \mathrm{CRVT}, \mathrm{KK}$, and $\mathrm{KH}$ provided review of the manuscript and contributed to the final write-up. SdeL was the senior study investigator. All authors read and approved the final manuscript.

\section{Acknowledgements}

The authors would like to thank Mert Senkal for his extensive assistance with data processing and Lucilla Butler for review of the final manuscript. The original QICKD trial work was funded by the Health Foundation and Edith Murphy Trust. This work was funded by the Department of Healthcare Management and Policy, University of Surrey.

\section{Author details}

${ }^{1}$ Department of Healthcare Management and Policy, University of Surrey, Guildford, UK. ${ }^{2}$ South West Thames Renal and Transplantation Unit, St Helier Hospital, Carshalton, UK. ${ }^{3}$ Southmead Hospital, North Bristol NHS Trust, Bristol, UK. ${ }^{4} J o h n$ Walls Renal Unit, University Hospitals of Leicester NHS Trust, Leicester General Hospital, Leicester, UK.

Received: 21 May 2013 Accepted: 23 May 2013

Published: 18 September 2013

\section{References}

1. Kannel WB, McGee DL: Diabetes and cardiovascular risk factors: the Framingham study. Circulation 1979, 59:8-13.

2. Sarwar N, Gao P, Seshasai SR, et al: Diabetes mellitus, fasting blood glucose concentration, and risk of vascular disease: a collaborative metaanalysis of 102 prospective studies. Lancet 2010, 375:2215-2222.

3. Foley RN, Collins AJ: End-stage renal disease in the United States: an update from the United States renal data system. J Am Soc Nephrol 2007, 18:2644-2648

4. Go AS, Chertow GM, Fan D, McCulloch CE, Hsu CY: Chronic kidney disease and the risks of death, cardiovascular events, and hospitalization. $N$ Engl J Med 2004, 351:1296-1305.

5. Weiner DE, Tighiouart $H$, Amin MG, et al: Chronic kidney disease as a risk factor for cardiovascular disease and all-cause mortality: a pooled analysis of community-based studies. J Am Soc Nephrol 2004, 15:1307-1315.

6. So WY, Kong AP, Ma RC, et al: Glomerular filtration rate, cardiorenal end points, and all-cause mortality in type 2 diabetic patients. Diabetes Care 2006, 29:2046-2052.

7. Mahmoodi BK, Matsushita K, Woodward M, et al: Associations of kidney disease measures with mortality and end-stage renal disease in individuals with and without hypertension: a meta-analysis. Lancet 2012, 380(9854):1649-1661.

8. van der Velde M, Matsushita K, Coresh J, et al: Lower estimated glomerular filtration rate and higher albuminuria are associated with all-cause and cardiovascular mortality. A collaborative meta-analysis of high-risk population cohorts. Kidney Int 2011, 79:1341-1352.

9. Fox CS, Matsushita K, Woodward M, et al: Associations of kidney disease measures with mortality and end-stage renal disease in individuals with and without diabetes: a meta-analysis. Lancet 2012, 380:1662-1673.

10. National Institute for Health and Clinical Excellence: Early identification and management of chronic kidney disease in adults in primary and secondary care. London: National Institute for Health and Clinical Excellence; 2008.

11. New JP, Middleton RJ, Klebe B, et al: Assessing the prevalence, monitoring and management of chronic kidney disease in patients with diabetes compared with those without diabetes in general practice. Diabet Med 2007, 24:364-369.

12. UK Prospective Diabetes Study Group: Tight blood pressure control and risk of macrovascular and microvascular complications in type 2 diabetes: UKPDS 38. BMJ 1998, 317:703-713.

13. Ahmad J, Siddiqui MA, Ahmad H: Effective postponement of diabetic nephropathy with enalapril in normotensive type 2 diabetic patients with microalbuminuria. Diabetes care 1997, 20:1576-1581.

14. Chan JC, Ko GT, Leung DH, et al: Long-term effects of angiotensinconverting enzyme inhibition and metabolic control in hypertensive type 2 diabetic patients. Kidney Int 2000, 57:590-600.

15. Ravid M, Brosh D, Levi Z, Bar-Dayan Y, Ravid D, Rachmani R: Use of enalapril to attenuate decline in renal function in normotensive, normoalbuminuric patients with type 2 diabetes mellitus. A randomized, controlled trial. Ann Intern Med 1998, 128:982-988.

16. Ravid M, Lang R, Rachmani R, Lishner M: Long-term renoprotective effect of angiotensin-converting enzyme inhibition in non-insulin-dependent diabetes mellitus. A 7-year follow-up study. Arch Intern Med 1996, 156:286-289.

17. de Zeeuw D, Remuzzi G, Parving HH, et al: Proteinuria, a target for renoprotection in patients with type 2 diabetic nephropathy: lessons from RENAAL. Kidney Int 2004, 65:2309-2320.

18. de Lusignan $\mathrm{S}$, Gallagher $\mathrm{H}$, Jones $\mathrm{S}$, et al: Audit-based education lowers systolic blood pressure in chronic kidney disease: the quality improvement in CKD (QICKD) trial results. Kidney Int 2013. Epub ahead of print.

19. de Lusignan S, Gallagher H, Chan T, et al: The QICKD study protocol: a cluster randomised trial to compare quality improvement interventions to lower systolic BP in chronic kidney disease (CKD) in primary care. Implement Sci 2009, 4:39.

20. de Lusignan S, Khunti K, Belsey J, et al: A method of identifying and correcting miscoding, misclassification and misdiagnosis in diabetes: a pilot and validation study of routinely collected data. Diabet Med 2010, 27:203-209.

21. World Health Organisation: Definition, diagnosis and classification of diabetes mellitus and its complications. Part 1: diagnosis and classification of diabetes mellitus. Geneva: World Health Organisation; 1999.

22. World Health Organisation: Use of glycated haemoglobin ( $\mathrm{HbA1C}$ ) in the diagnosis of diabetes mellitus. Geneva: World Health Organisation; 2011

23. de Lusignan S, Chan T: The development of primary care information technology in the United kingdom. J Ambul Care Manage 2008, 31:201-210.

24. Schade CP, Sullivan FM, de Lusignan S, Madeley J: E-Prescribing, efficiency, quality: lessons from the computerization of UK family practice. J Am Med Inform Assoc 2006, 13:470-475.

25. Department for Communities and Local Government: The english indices of deprivation 2007. London: Department for Communities and Local Government; 2008

26. National Institute for Health and Clinical Excellence: Hypertension: clinical management of primary hypertension in adults. London: National Institute for Health and Clinical Excellence: 2011.

27. National Institute for Health and Clinical Excellence: Type 2 diabetes: the management of type 2 diabetes (update). London: National Institute for Health and Clinical Excellence; 2008

28. National Institute for Health and Clinical Excellence: Diagnosis and management of type 1 diabetes in children, young people and adults. London: National Institute for Health and Clinical Excellence; 2004.

29. Abutaleb N: Why we should sub-divide CKD stage 3 into early (3a) and late (3b) components. Nephrol Dial Transplant 2007, 22:2728-2729.

30. National Institute for Health and Clinical Excellence: Chronic kidney disease. Early identification and management of chronic kidney disease in adults in primary and secondary care. London: National Institute for Health and Clinical Excellence; 2008.

31. Lamb EJ, MacKenzie F, Stevens PE: How should proteinuria be detected and measured? Ann Clin Biochem 2009, 46:205-217.

32. Bates $D$, Maechler M, Bolker B: Ime4: linear mixed-effects models using S4 classes. 2012 [http://cran.r-project.org/web/packages/lme4/index.html]

33. Maindonald J, Braun J: Data analysis and graphics using $R$ : an example-based approach (Cambridge series in statistical and probabilistic mathematics). Cambridge: Cambridge University Press; 2010.

34. de Lusignan S, Sadek N, Mulnier H, Tahir A, Russell-Jones D, Khunti K: Miscoding, misclassification and misdiagnosis of diabetes in primary care. Diabet Med 2012, 29:181-189.

35. Collins AJ, Vassalotti JA, Wang C, et al: Who should be targeted for CKD screening? impact of diabetes, hypertension, and cardiovascular disease. Am J Kidney Dis 2009, 53:S71-S77

36. Islam TM, Fox CS, Mann D, Muntner P: Age-related associations of hypertension and diabetes mellitus with chronic kidney disease. BMC Nephrol 2009, 10:17.

37. Middleton RJ, Foley RN, Hegarty J, et al: The unrecognized prevalence of chronic kidney disease in diabetes. Nephrol Dial Transplant 2006, 21:88-92.

38. Hassan Sadek N, Sadek AR, Tahir A, Khunti K, Desombre T, de Lusignan S: Evaluating tools to support a new practical classification of diabetes: excellent control may represent misdiagnosis and omission from disease registers is associated with worse control. Int J Clin Pract 2012, 66:874-882 
39. Astor BC, Matsushita K, Gansevoort RT, et al: Lower estimated glomerular filtration rate and higher albuminuria are associated with mortality and end-stage renal disease. A collaborative meta-analysis of kidney disease population cohorts. Kidney Int 2011, 79:1331-1340

40. Matsushita $K$, van der Velde M, Astor BC, et al: Association of estimated glomerular filtration rate and albuminuria with all-cause and cardiovascular mortality in general population cohorts: a collaborative meta-analysis. Lancet 2010, 375:2073-2081.

41. Barkoudah E, Skali H, Uno H, Solomon SD, Pfeffer MA: Mortality rates in trials of subjects with type 2 diabetes. J Am Heart Assoc 2012, 1:8-15.

42. de Lusignan $\mathrm{S}$, van Weel C: The use of routinely collected computer data for research in primary care: opportunities and challenges. Fam Pract 2006, 23:253-263.

43. de Lusignan S, Tomson C, Harris K, van Vlymen J, Gallagher H: Creatinine fluctuation has a greater effect than the formula to estimate glomerular filtration rate on the prevalence of chronic kidney disease. Nephron Clin Pract 2011, 117:c213-c224.

doi:10.1186/1471-2369-14-198

Cite this article as: McGovern et al: Association of chronic kidney disease (CKD) and failure to monitor renal function with adverse outcomes in people with diabetes: a primary care cohort study. BMC Nephrology 2013 14:198.

\section{Submit your next manuscript to BioMed Central and take full advantage of:}

- Convenient online submission

- Thorough peer review

- No space constraints or color figure charges

- Immediate publication on acceptance

- Inclusion in PubMed, CAS, Scopus and Google Scholar

- Research which is freely available for redistribution 